\title{
Children were less frequently infected with SARS-CoV-2 than adults during 2020 COVID-19 pandemic in Warsaw, Poland
}

\author{
Ernest Kuchar ${ }^{1}$ - Andrzej Załęski ${ }^{2,3} \cdot$ Michał Wronowski $^{1} \cdot$ Dagny Krankowska ${ }^{2,3}$ • Edyta Podsiadły ${ }^{4}$. \\ Klaudia Brodaczewska ${ }^{5}$. Aneta Lewicka ${ }^{6}$. Sławomir Lewicki ${ }^{7}$. Claudine Kieda ${ }^{5,8}$ - Andrzej Horban ${ }^{3}$. \\ Małgorzata Kloc ${ }^{9,10,11}$ • Jacek Z. Kubiak ${ }^{7,12}$ (1)
}

Received: 16 June 2020 / Accepted: 10 September 2020 / Published online: 28 September 2020

(C) Springer-Verlag GmbH Germany, part of Springer Nature 2020

\begin{abstract}
Clinical data suggest that during the current COVID-19 pandemic, children are less prone than adults to SARS-CoV-2 infection. Our purpose was to determine the frequency of SARS-CoV-2 in children vs. adults during the 2020 pandemic in Warsaw, Poland, and to investigate whether RSV and/or influenza A/B infections were associated with SARS-CoV-2 infections. We present results of RT-PCR tests for SARS-CoV-2 performed in Warsaw, Poland. Some of the pediatric subjects were also PCRtested for RSV, and A and B influenza. We compared the test results from the four groups of symptomatic and asymptomatic subjects: 459 symptomatic pediatric patients (children 0-18 years old), 1774 symptomatic adults, 445 asymptomatic children, and 239 asymptomatic adults. $3.26 \%$ (15/459) of symptomatic pediatric patients were positive for SARS-CoV-2 in contrast to $5.58 \%(99 / 1774)$ of symptomatic adults $(p=0.0448)$. There were no SARS-CoV-2 positive cases in the group of asymptomatic children $(0 / 445)$ and two positive cases in the group of asymptomatic adults $(2 / 239)$, i.e., $0.83 \%$. In the group of symptomatic pediatric patients, $17.14 \%(6 / 35)(p=0.0002)$ were positive for RSV, $8.16 \%(4 / 49)$ were positive for influenza A, and $2.04 \%$ $(1 / 49)$, thus $10.20 \%(5 / 49)(p=0.0176)$ for influenza A/B. Children were less prone to SARS-CoV-2 infection than the adults during the COVID-19 pandemic in Warsaw. Higher percentage of symptomatic children was infected with RSV or influenza A/B than with SARS-CoV-2. This suggests a necessity for the testing for all these viruses for an early identification and isolation of SARS-CoV-2-positive patients for an ensuing 2020 autumn return of COVID-19.
\end{abstract}

Keywords COVID-19 $\cdot$ SARS-CoV-2 2020 pandemic $\cdot$ Pediatric patients

Electronic supplementary material The online version of this article (https://doi.org/10.1007/s10096-020-04038-9) contains supplementary material, which is available to authorized users.

Jacek Z. Kubiak

jacek.kubiak@univ-rennes1.fr

1 Department of Paediatrics with Clinical Assessment Unit, Medical University of Warsaw, Warsaw, Poland

2 Department of Infectious Diseases, Tropical Diseases and Hepatology, Medical University of Warsaw, Warsaw, Poland

3 Hospital of Infectious Diseases, Warsaw, Poland

4 Department of Laboratory Diagnostics and Clinical Immunology of Developmental Age, Public Paediatric Teaching Hospital, Warsaw, Poland

5 Laboratory of Molecular Oncology and Innovative Therapies, Military Institute of Medicine, Szaserów 128, 01-163 Warsaw, Poland

6 Laboratory of Food and Nutrition Hygiene, Military Institute of Hygiene and Epidemiology (WIHE), Kozielska 4, 01-163 Warsaw, Poland
7 Department of Regenerative Medicine and Cell Biology, Military Institute of Hygiene and Epidemiology (WIHE), Kozielska 4, Warsaw, Poland

8 Centre for Molecular Biophysics, Cell Recognition and Glycobiology, UPR4301-CNRS, rue Charles Sadron, 45071 Orléans, France

9 The Houston Methodist Research Institute, Houston, TX, USA

10 Department of Surgery, The Houston Methodist Hospital, Houston, TX, USA

11 Department of Genetics, M.D. Anderson Cancer Center, The University of Texas, Houston, TX, USA

12 UnivRennes, CNRS, UMR 6290, Institute of Genetics and Development of Rennes (IGDR), Cell Cycle Group, Faculty of Medicine, Rennes, 35043 cedex, France 


\section{Introduction}

Severe acute respiratory syndrome coronavirus-2 or SARSCoV-2 emerged in Wuhan in Hubei Province in China in December 2019 and rapidly had propagated all over the world causing the COVID-19 pandemic, declared by WHO in March 11 (WHO Director-General's opening remarks at the media briefing on COVID-19-11 March [37]; https://www. who.int/dg/speeches/detail/who-director-general-s-openingremarks-at-the-media-briefing-on-covid-19\%2D\%2D-11march-2020). The pandemic and number of cases are still unfolding in many countries while we report this data. In Poland, the first case was reported on March 4th, 2020. During the first 2 weeks of the epidemic, the whole Masovia area, including the Polish capital, Warsaw, became one of the major infected areas in Poland, with 3581 cases by 1 st June 2020 .

There is a growing body of evidence from different countries with COVID-19 pandemic that children are less frequently infected with SARS-CoV-2. Children are mostly asymptomatic or experience much milder symptoms than the adults $[1,7,9,12,15,19,21,41]$, although a low percentage of the infected children developed the pediatric multi-system inflammatory syndrome [34]. Severe (2-3\%) or critical illness $(0.61 \%)$ has been reported in pediatric patients analyzed in two systematic reviews and meta-analysis of data from several countries $[8,17]$. The purpose of our study was to establish if a lower frequency of infection, and lesser severity in children were also true for the 2020 COVID-19 pandemic in Warsaw, Poland.

\section{Material and methods}

\section{Patients}

Analyses were performed on two main groups of patients: children, from 1 month to 18 years old, and adults, over 18 years old. Patients from two Warsaw hospitals were enrolled: the Pediatric Teaching Clinical Hospital of Medical University of Warsaw and the Hospital for Infectious Diseases (Warsaw, Poland). Each of these two groups was divided into two subgroups: symptomatic (separately children and adults) and asymptomatic (separately children and adults). Patients presenting with fever, respiratory tract infection syndromes, gastrointestinal symptoms, dyspnea, cough, chest pain, and seizures were included in the symptomatic groups. Two asymptomatic groups were the following: (1) asymptomatic children who underwent screening for SARS-CoV-2 at the admission for planned hospitalization unrelated to COVID-19, (2) asymptomatic legal guardians of the asymptomatic children and medical staff involved in contact tracing.

\section{SARS-CoV-2 analysis}

Throat or nasopharynx swabs were obtained from the symptomatic and asymptomatic subjects. Immediately after collection, the swabs were placed in viral preservation medium, transported to laboratory in temperature $2-8{ }^{\circ} \mathrm{C}$, and stored in such conditions until processing. Total RNA was extracted from $140 \mu \mathrm{l}$ specimen with manual centrifuge column isolation kit (Viral RNA Isolation Kit, ZJ Bio-Tech C, China) according to manufacturer's instruction. Extraction volume of $60 \mu \mathrm{l}$ was obtained for each sample. A $5 \mu \mathrm{l}$ aliquot of RNA was used for real-time RT-PCR, which targeted simultaneously 3 genes specific for SARS-CoV-2: gene E, N, and ORF1ab (Liferiver Novel Coronavirus (2019-nCoV) Real Time Multiplex RT-PCR Kit, Shanghai ZJ Bio-Tech C, Shanghai, China). Real-time PCR was performed upon CFX96 TM Real-Time PCR Detection System (Bio-Rad, USA). The specificity of the test is $98.1 \%$, analytical sensitivity $1 \times 10^{3} \mathrm{copies} / \mathrm{ml}$. The protocol was performed according manufacturer's instruction. Real-time RT-PCR was performed under the following conditions: $45^{\circ} \mathrm{C}$ for $10 \mathrm{~min}$ and $95^{\circ} \mathrm{C}$ for $15 \mathrm{~min}$, followed by 45 cycles of amplification at 95 ${ }^{\circ} \mathrm{C}$ for $15 \mathrm{sec}$ and $60^{\circ} \mathrm{C}$ for $1 \mathrm{~min}$. Criteria for judging results: CT value $<43$ positive; $43 \leq \mathrm{CT}$ value $\leq 45$ suspicious positive and $\geq 45$ negative. The positive should meet for all 3 genes tested. Internal control was added into extraction mixture on isolation stage to monitor the whole process. Positive and negative control was included in each run of amplification.

\section{RSV and influenza A/B analysis}

Selected samples of pediatric symptomatic patients were also tested for the presence of RSV and Influenza A/B virus with qualitative real-time PCR test Xpert@ Xpress Flu/RSV (Cepheid, USA). 35 patients were tested for RSV and 49 patients for influenza A and B. Nasopharyngeal specimen were collected from selected pediatric symptomatic patients. After collection the swab were placed in universal transport medium (UTM, Copan Diagnostics). The samples were tested immediately after collection with qualitative real-time PCR test Xpert ${ }^{\circ}$ Xpress Flu/RSV (Cepheid, USA) according manufacturer's instruction on GeneXpert I apparatus. The volume of $300 \mu \mathrm{l}$ was transferred to the cartridge. Isolation and amplification stage was done automatically by the instrument. Each test was equipped in internal control which monitored whole process. External positive and negative controls were tested with each new applied lot of Xpert Xpress Flu/RSV. The RTPCR test targets few genes of examined viruses: genes encoding matrix protein, $\mathrm{PB} 2$ and $\mathrm{PA}$ for Flu $\mathrm{A}$, genes encoding matrix protein and non-structural protein for fly $\mathrm{B}$, genes encoding nucleocapsid of RSV A and RSV B. Sensitivity of the test is estimated on $99 \%$, specificity on $98 \%$. 
Results were presented as the percentage of all patients in the given group.

\section{Statistical analysis}

The data from the adults and children, as well as RSV positive, and influenza A and B positive cases within the selected samples in the symptomatic children group, were analyzed by chisquare test. The $p$ value $<0.05$ was considered statistically significant. We also analyzed data using the Fisher test.

\section{Results}

SARS-CoV-2 RT-PCR tests were performed in two centers in Warsaw, Poland, during 3 months between March and May 2020, which corresponded to the first 3 months of COVID-19 epidemics in Poland. Patients were divided into four groups.

1. Symptomatic pediatric patients $(n=459)$,

2. Symptomatic adult patients $(n=1774)$,

3. Asymptomatic children $(n=445)$,

4. Asymptomatic adults $(n=239)$.

The age strata in each group are showed in Supplementary Materials 1 section.

The tests showed $3.26 \%$ (15/459) positive cases among the symptomatic pediatric patients, 5.58\% (99/1774) among the symptomatic adults, none in the asymptomatic children $(0 / 445)$, and $0.83 \%(2 / 239)$ in the asymptomatic adults.

The statistical analysis performed with the chi-square test has shown significantly ( $p=0.0448$ ) lower incidence of SARS-CoV-2 infection in the symptomatic pediatric population than in the symptomatic adults. This trend was also observed in the asymptomatic groups, however the result was not statistically significant ( $p=0.0533$ ) (Fig. 1). The Fisher test analysis gave similar results (Fig. 1 Suppl. Materials).

The age of 15 positive pediatric symptomatic patients, uniformly covering the whole period between 0.6 and 14.1 years of age, was as follows: 0.6, 06, 0.8, 1.0, 1.8, 4.2, 5.0, 7.3, 9.8, $10.0,11.0,11.3,13.0,14.0$, and 14.1 years.

The analysis of the symptomatic non-SARS-CoV-2 patients showed that $17.14 \%(6 / 35)(p=0.0002)$ of children were positive for RSV, $8.16 \%$ (4/49) for influenza A, and $2.04 \%(1 / 49)$ for influenza B; thus, $10.20 \%(5 / 49)(p=$ 0.0176 ) were positive for $A$ and $B$ influenza together (the same 49 patients were tested for influenza $A$ and B). These data were also analyzed using two statistical tests: chi-square (Fig. 2) and the Fisher test (Fig. 2 Suppl. Materials). In other words, $17.14 \%$ of pediatric patients negative for SARS-CoV2 were positive for RSV, and $10.20 \%$ for influenza A/B. Thus, a statistically significantly higher number of pediatric symptomatic patients were positive for either RSV or influenza A/B than for SARS-CoV-2. There was also a single pediatric case of pertussis (whooping cough) diagnosed based on the clinical symptoms. These data show that during the first three months (March-May 2020) of the COVID-19 pandemic in Warsaw, Poland, significantly less pediatric patients were infected with SARS-CoV-2 than RSV and influenza together. Thus, children were more likely to be infected with RSV or influenza A/B than with SARS-CoV-2.

\section{Discussion}

Our study showed that children presenting symptoms suggestive of COVID-19 and requiring hospitalization or an emergency assessment, had significantly lower SARS-CoV-2 infection than hospitalized adults. This data are consistent with the previous studies from different countries during the 2020 COVID-19 pandemic. Asymptomatic, mild, and moderate symptoms were observed in more than $90 \%$ of all COVID19 positive children; severe and critical cases were observed in $5.9 \%$ of children in comparison to $18.5 \%$ in adults [9]. Cristiani et al. [7] report that among the total number of 44,672 positive cases, the Chinese Centre of Disease Control and Prevention report showed only 416 pediatric cases in 0-9 years age group $(0.9 \%)$ with no fatalities and 549 cases in 10 19 years age group (1.2\%) with 1 fatality $(0.2 \%)$. Brodin [3] reports Korean data showing that $6.3 \%$ of all positive cases were children under 19 years of age. (reviewed also by [1, 12, $15,19,21,41])$.

Interestingly, SARS-CoV-1 infection rate during 20022003 epidemic had shown similar characteristics regarding children vs. adults in China, and other countries [5, 9, 29, 30, 40]. Therefore, it seems that children are more resistant to both SARS-CoV-1 and SARS-CoV-2 infection.

There are several factors that might explain this phenomenon. First of all, children, because the milder symptoms of SARS-CoV-2 infection are tested less frequently than the adults. There may be also an input from the environmental/ social factors. Children may be better protected and sheltered against the virus during the pandemic than the adults, and the rate of children infection may be influenced by the quality of the parental care [41].

Alternatively, some endogenous factors may play a role. They may include a different age-dependent expression and/or distribution of ACE2 receptor for SARS-CoV-1 and SARSCoV-2 (suggested by [3, 16, 18, 20, 31, 33, 35, 38, 39]). Indeed, a lower level of ACE2 expression in the nasal epithelial cells of children, especially the youngest children, was confirmed by a recent study of Bunyavanich [4] suggesting that this can be a reason for a lower infectability of children with SARS viruses. Nevertheless, the data about the impact of ACE2 expression pattern are still fragmentary. 


\section{a Symptomatic patients}

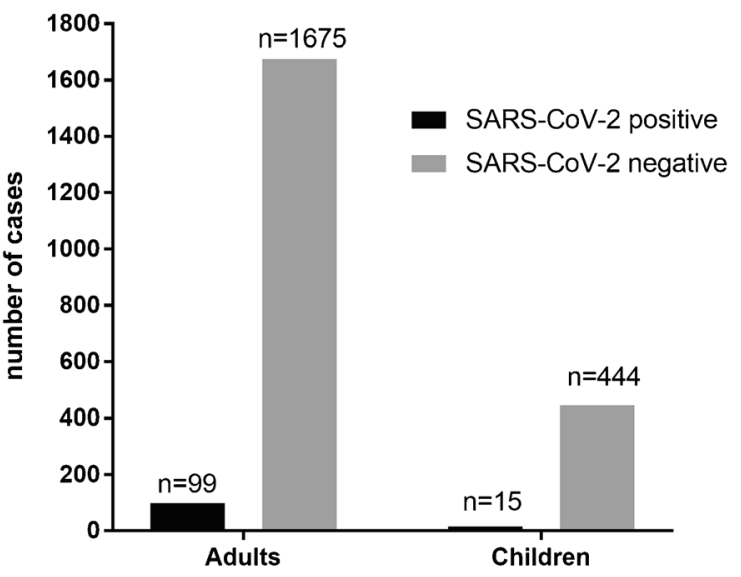

\begin{tabular}{|l|l|}
\hline P value and statistical significance & \\
\hline Test & Chi-square \\
\hline Chi-square, df & $4.026,1$ \\
\hline Z & 2.006 \\
\hline P value & 0.0448 \\
\hline P value summary & * \\
\hline One- or two-sided & Two-sided \\
\hline Statistically significant $(P<0.05) ?$ & Yes \\
\hline
\end{tabular}

\section{b Asymptomatic patients}

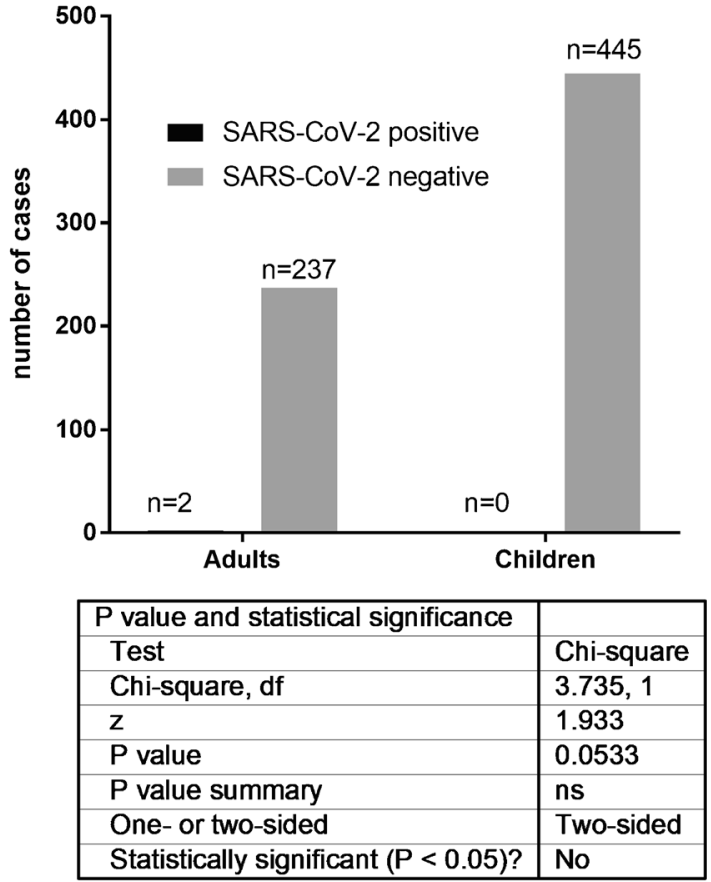

Fig. 1 The statistical analysis by chi-square test of the results obtained in a symptomatic patients and $\mathbf{b}$ asymtomaptic patients

One of the reasons for the severity of the COVID-19 is the over-reactivity of the immune response in the lungs, where the alveolar macrophages induce the cytokine storm [13]. In children, the immune system is immature [13], thus aggressive cytokine response is rarely seen [28] resulting in milder COVID-19 symptoms. The severity of COVID-19 in children was recently reviewed by two meta-analyses $[8,17]$. Even though the reviews had large cohorts (7480, 4857 patients), the severity of illness was described only in $20-34 \%$ of all patients (1475 and 1666 respectively). In the review by Liguoro et al. [17], $12 \%$ of neonates were severely ill. In the second review, neonates were not included in the study. The estimated reported mortality in these two studies was $0.08 \%$ and $0.1 \%$ of analyzed patients. Higher morbidity and mortality ratios were described by the ptbnet COVID-19 study Group who collected data from 25 European countries during the peak of the pandemic in Europe in April 2020 [10]. Out of 582 patients, $8 \%$ required ICU admission, and $4 \%$ required a

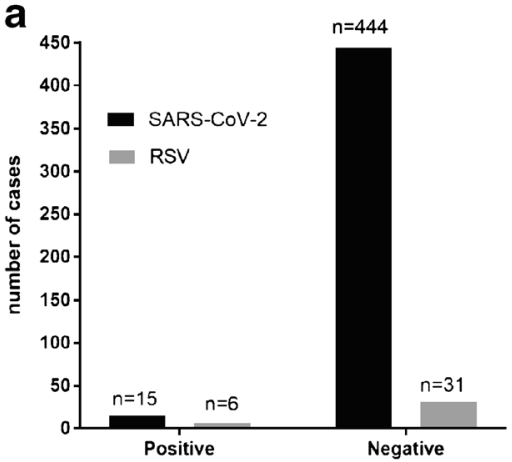

\begin{tabular}{|l|l|}
\hline $\begin{array}{l}\text { P value and statistical significance } \\
\text { Test }\end{array}$ & Chi-square \\
\hline Chi-square, df & $14.16,1$ \\
\hline$z$ & 3.763 \\
\hline$P$ value & 0.0002 \\
\hline P value summary & $\star \star \star$ \\
\hline One- or two-sided & Two-sided \\
\hline Statistically significant $(P<0.05) ?$ & Yes \\
\hline
\end{tabular}
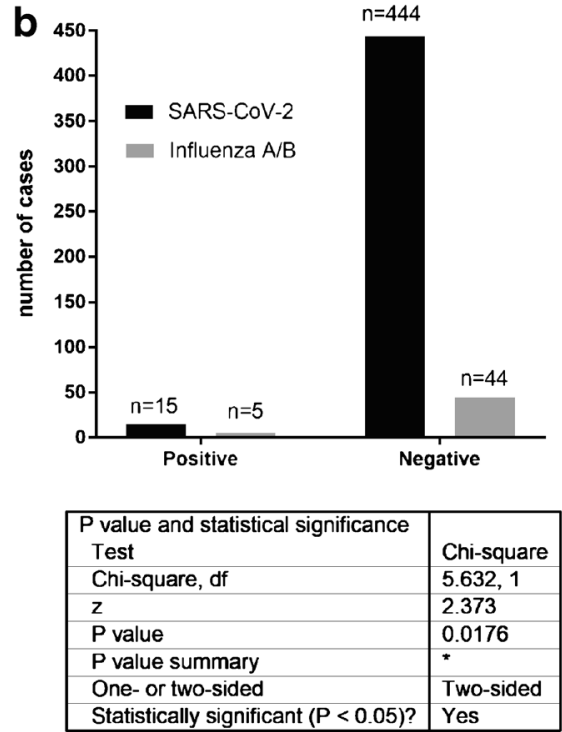

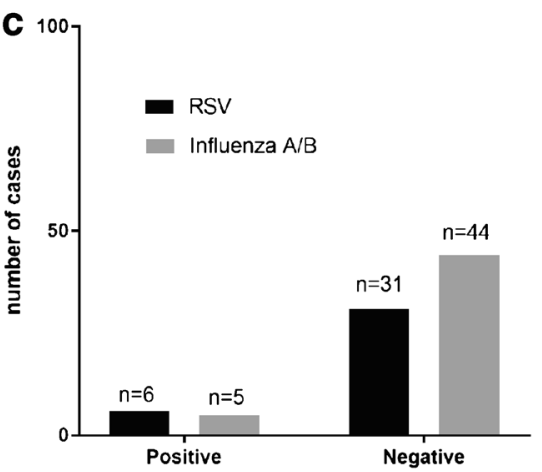

\begin{tabular}{|l|l|}
\hline$P$ value and statistical significance & \\
\hline Test & Chi-square \\
\hline Chi-square, df & $0.6831,1$ \\
\hline$Z$ & 0.8265 \\
\hline$P$ value & 0.4085 \\
\hline$P$ value summary & ns \\
\hline One- or two-sided & Two-sided \\
\hline Statistically significant $(P<0.05)$ ? & No \\
\hline
\end{tabular}

Fig. 2 The statistical analysis by chi-square test of the results obtained in a SARS-CoV-2 vs. RSV tests, $\mathbf{b}$ SARS-CoV-2 vs. influenza A/B, and $\mathbf{c}$ RSV vs. influenza $\mathrm{A} / \mathrm{B}$ 
mechanical ventilation. The case fatality rate was $0.69 \%$, and age younger than 1 month, male sex, signs or symptoms of lower respiratory tract infections at presentation, and the presence of pre-existing medical conditions were associated with ICU admission.

Another plausible explanation might be that the children who attend day-care, kindergarten, and school and are frequently exposed to the respiratory viruses, develop some basal level of the antibodies, which give cross protection against SARS-CoV-2 [26].

In the case of newborns, and very young babies, a part of explanation can be that they are protected either by antibodies transferred during pregnancy through the placenta from mother $[3,11,24]$. or the compounds, such as the lactoferrin, a globular glycoprotein present in the breast milk that have the antimicrobial and immunomodulatory roles in protecting the newborn from the various infections [32], including the necrotizing enterocolitis [27] and SARS [14].

A plausible hypothesis for a lower number of positive cases among children is that a high percentage of them might have been protected by the cross-immunity conferred by infections with other viruses including human coronaviruses (e.g. [3]). Also, the vaccination against other infectious diseases may stimulate the cross-immunity. The young patients were probably better protected because of freshly acquired immune memory [20]. Of special interest can be the so-called trained immunity caused by vaccinations with live viruses, such as OPV, anti-measles vaccine, or mycobacteria, including BCG $[6,22]$. Moreover, the authors also hypothesized that if SARSCoV-2 will mutate, and the specific vaccine will be weak or ineffective, the OPV may be the only real solution in the future [6]. In this case, again, recent vaccination might give a better protective effect.

Interestingly, the PCR tests of children included in our study showed that, within the first three months of the COVID-19 pandemic in Warsaw, the children had significantly higher risk for RSV or influenza A/B than for SARS-CoV-2 infection. If this bias toward RSV and influenza $\mathrm{A} / \mathrm{B}$ infection persists for the next seasonal peak of flu, and respiratory infections, the physicians in Masovia area should keep in mind that the common flu/respiratory infections are much more frequent than COVID-19. However taking into account the risk of spreading COVID-19, authorities should perform a routine broad testing for all these viruses. The data from many countries show that an early detection of SARS-CoV-2 infection is one of the most effective strategies of pandemic control.

In addition, our study did not show any case of the coinfection between SARS-CoV-2 and other viruses tested, or between RSV and Influenza A/B. Reina and Dueñas [25] showed that the RSV and influenza coinfection occurred in $4.8 \%$ of the total studied RSV cases. It is possible that the limited number of pediatric patients, which were tested for RSV and Influenza A/B in our study is responsible for this discrepancy. In contrast, some studies have reported the presence of coinfections with SARS-CoV-2 and other respiratory tract pathogens, both in children and adults. In most cases studied, the researchers have reported coinfection with others than SARS-CoV-2 coronaviruses (HKU1, NL63, 229E, OC43), influenza, and parainfluenza viruses, RSV, rhinoviruses-enteroviruses, human methapneumoviruses, adenoviruses, and Mycoplasma pneumoniae. Nevertheless, the coinfection rates were low and ranged between $0.1 \%-3 \%$, and the studies did not clearly assess whether they influenced the course of infection with SARS-CoV-2 or not. In general, the clinical course was mild, ending with full recovery $[2,23,36]$.

We want to emphasize some limitations of our study. First, the number of examined patients was not very high. We wanted to present our results as quickly as possible to spread the information included in this article before the onset of the expected autumn/winter wave of the pandemic, and for this reason, we have chosen to describe the results of the first 3 months of the pandemic. It allows to draw conclusions, but further studies should be performed to verify whether the observed percentage of children vs. adults infections is similar during the whole period of the pandemic period without the anti-SARS-CoV-2 vaccination.

\section{Conclusions}

The results of our study are consistent with the previous data showing that SARS-CoV-2 infection in children occurs less often than in the adults. Routine testing for SARS-CoV-2 is crucial for the control of the pandemic, and discerning between COVID-19 and common seasonal respiratory infections.

Acknowledgments We acknowledge the funding from the Polish Ministry of National Defense "Kościuszko" \# 5508/2017/DA grant to JZK.

Authors' contributions EK, AL, SL, MK, and JZK designed the study. AZ, MW, and DK performed tests; MK and JZK wrote the manuscript; EK, AZ, MW, DK, EP, KB, AL, SL, CK, AH, and JZK analyzed results; $\mathrm{AL}$ and SL performed the statistical analysis; EK, AZ, MW, DK, EP, AL, $\mathrm{SL}, \mathrm{CK}, \mathrm{AH}, \mathrm{MK}$, and JZK edited the manuscript.

Funding JZK was supported by Polish Ministry of National Defense "Kościuszko" \# 5508/2017/DA grant while preparing this manuscript.

Data availability All data and material are freely available.

\section{Compliance with ethical standards}

Conflict of interest The authors declare that they have no conflict of interest. 
Ethical approval No ethical approval was obtained because this study did not involve a clinical evaluation and did not involve laboratory animals and invasive procedures.

\section{References}

1. Balasubramanian S, Rao NM, Goenka A, Roderick M, Ramanan AV (2020) Coronavirus disease (COVID-19) in children-what we know so far and what we do not? Indian Pediatr 57(5):435-442

2. Blasco ML et al (2020) Co-detection of respiratory pathogens in patients hospitalized with coronavirus viral disease-2019 pneumonia. J Med Virol 92:1799-1801

3. Brodin P (2020) (2020). Why is COVID-19 so mild in children? Acta Paediatr. 109(6):1082-1083. https://doi.org/10.1111/apa. 15271

4. Bunyavanich S (2020) Nasal gene expression of angiotensinconverting enzyme 2 in children and adults. JAMA 323(23): 2427-2429. https://doi.org/10.1001/jama.2020.8707

5. Cao L, Wang TY, Chen HZ, Qian Y, Chen BW, Fang P, Sun YX, Zhu RN, Deng J, Zhao LQ, Mi J, Zhang T (2004) [A preliminary investigation on the serological and epidemiological characteristics of severe acute respiratory syndrome in children]. [Article in Chinese]. Zhonghua Er Ke Za Zhi 42(11):840-844

6. Chumakov K, Benn CB, Aaby P, Kottilil S, Gallo R (2020) Can existing live vaccines prevent COVID-19? Science 368(6496): 1187-1188. https://doi.org/10.1126/science.abc4262

7. Cristiani L, Mancino E, Matera L, Nenna R, Pierangeli A, Scagnolari C, Midulla F (2020) Will children reveal their secret? The coronavirus dilemma. Eur Respir J 2020:2000749. https://doi. org/10.1183/13993003.00749-2020

8. Dhir SK, Kumar J, Meena J, Kumar P (2020) Clinical features and outcome of SARS-CoV-2 infection in neonates: a systematic review. J Trop Pediatr 1-14. https://doi.org/10.1093/tropej/fmaa059

9. Dong Y, Mo X, Hu Y, et al (2020) Epidemiological characteristics of 2143 pediatric patients with 2019 coronavirus disease in China. Pediatrics e20200702. https://doi.org/10.1542/peds.2020-0702

10. Götzinger F, Santiago-García B, Noguera-Julián A, Lanaspa M, Lancella L, Calò Carducci FI, Gabrovska N, Velizarova S, Prunk P, Osterman V, Krivec U, Lo Vecchio A, Shingadia D, SorianoArandes A, Melendo S, Lanari M, Pierantoni L, Wagner N, L'Huillier AG, Heininger U, Ritz N, Bandi S, Krajcar N, Roglić S, Santos M, Christiaens C, Creuven M, Buonsenso D, Welch SB, Bogyi M, Brinkmann F, Tebruegge M, ptbnet COVID-19 Study Group (2020) COVID-19 in children and adolescents in Europe: a multinational, multicentre cohort study. Lancet Child Adolesc Health 4(9):653-661

11. Jackson KM, Nazar AM (2006) Breastfeeding, the immune response, and long-term health. J Am Osteopath Assoc 106:203-207

12. Jiatong S, Lanqin L, Wenjun L (2020) COVID-19 epidemic: disease characteristics in children. J Med Virol 92(7):747-754. https:// doi.org/10.1002/jmv. 25807

13. Kloc M, Ghobrial RM, Kuchar E, Lewicki S, Kubiak JZ (2020) Development of child immunity in the context of COVID-19 pandemic. Clin Immunol 217:108510. https://doi.org/10.1016/j.clim. 2020.108510

14. Lang J, Yang N, Deng J, Liu K, Yang P, Zhang G, Jiang C (2011) Inhibition of SARS pseudovirus cell entry by lactoferrin binding to heparan sulfate proteoglycans. PLoS One 6(8):e23710

15. Lee $\mathrm{P}, \mathrm{Hu} \mathrm{YL}$, Chen PY et al (2020) Are children less susceptible to COVID-19? J Microbiol Immunol Infect S1684-1182(20):3003930036

16. Li W, Moore MJ, Vasilieva N, Sui J, Wong SK, Berne MA, Somasundaran M, Sullivan JL, Luzuriaga K, Greenough TC et al
(2003) Angiotensin-converting enzyme 2 is a functional receptor for the sars coronavirus. Nature 426:450-454

17. Liguoro I, Pilotto C, Bonanni M, Ferrari ME, Pusiol A, Nocerino A, Vidal E, Cogo P (2020) SARS-COV-2 infection in children and newborns: a systematic review. Eur J Pediatr. 179(7):1029-1046

18. Lovren F, Pan Y, Quan A, Teoh H, Wang G, Shukla PC, Levitt KS, Oudit GY, Al-Omran M, Stewart DJ et al (2008) Angiotensin converting enzyme- 2 confers endothelial protection and attenuates atherosclerosis. Am J Physiol Heart Circ Physiol 295:H1377H1384

19. Marraro GA, Spada C (2020) Consideration of the respiratory support strategy of severe acute respiratory failure caused by SARSCoV-2 infection in children. Zhongguo Dang Dai Er Ke Za Zhi. 22(3):183-194

20. Miri SM, Noorbakhsh F, Mohebbi SR, Ghaemi A (2020) Higher prevalence of asymptomatic or mild COVID-19 in children, claims and clues. J Med Virol 1-3. https://doi.org/10.1002/jmv.26069.

21. Morand A, Fabre A, Minodier P, Boutin A, Vanel N, Bosdure E, Fournier PE (2020) COVID-19 virus and children: what do we know? Arch Pediatr. 27(3):117-118. https://doi.org/10.1016/j. arcped.2020.03.001

22. Netea MG, Giamarellos-Bourboulis EJ, Domínguez-Andrés J, Curtis N, van Crevel R, van de Veerdonk FL, Bonten M (2020) Trained immunity: a tool for reducing susceptibility to and the severity of SARS-CoV-2 infection. Cell 181(5):969-977

23. Nowak MD, Sordillo EM, Gitman MR, Paniz Mondolfi AE (2020) Co-infection in SARS-CoV-2 infected Patients: Where are influenza virus and rhinovirus/enterovirus? J Med Virol 92:1699-1700. https://doi.org/10.1002/jmv.25953

24. Palmeira P, Quinello C, Lúcia Silveira-Lessa A, Zago A, CarneiroSampaio M (2012) IgG placental transfer in healthy and pathological Pregnancies. Clin Dev Immunol 2012:985646. Published online 2011 Oct 1. https://doi.org/10.1155/2012/985646

25. Reina J, Dueñas J (2019) [Respiratory co-infections between influenza viruses and respiratory syncytial virus (2014-2017)] [Article in Spanish]. An Pediatr (Barc). 90(2):118-119

26. Schuez-Havupalo L, Toivonen L, Karppinen S, Kaljonen A, Peltola V (2020) Daycare attendance and respiratory tract infections: a prospective birth cohort study. BMJ Open 7(9):e014635

27. Sherman MP (2013) Lactoferrin and necrotizing enterocolitis. Clin Perinatol. 40(1):79-91

28. Simon AK et al (2015) Evolution of the immune system in humans from infancy to old age. Proc Biol Sci 282(1821):20143085. https:// doi.org/10.1098/rspb.2014.3085

29. Sørensen MD, Sørensen B, Gonzalez-Dosal R, Melchjorsen CJ, Weibel J, Wang J, Jun CW, Huanming Y, Kristensen P (2006) Severe acute respiratory syndrome (SARS): development of diagnostics and antivirals. Ann N Y Acad Sci. 1067:500-505

30. Stockman LJ, Massoudi MS, Helfand R, Erdman D, Siwek AM, Anderson LJ, Parashar UD (2007) Severe acute respiratory syndrome in children. Pediatr Infect Dis J 26(1):68-74

31. Tai W, He L, Zhang X, Pu J, Voronin D, Jiang S, Zhou Y, Du L (2020) Characterization of the receptor-binding domain (rbd) of 2019 novel coronavirus: implication for development of rbd protein as a viral attachment inhibitor and vaccine. Cell Mol Immunol 17: 613-620. https://doi.org/10.1038/s41423-020-0400-4

32. Telang S (2018) Lactoferrin: a critical player in neonatal host defense. Nutrients 10(9):1228. https://doi.org/10.3390/nu10091228

33. Tipnis SR, Hooper NM, Hyde R, Karran E, Christie G, Turner AJ (2000) A human homolog of angiotensin-converting enzyme. Cloning and functional expression as a captopril-insensitive carboxypeptidase. J Biol Chem 275:33238-33243

34. Viner RM, Whittaker E (2020) Kawasaki-like disease: emerging complication during the COVID-19 pandemic. Lancet 395(10239):1741-1743. https://doi.org/10.1016/S0140-6736(20) $31129-6$ 
35. Walls AC, Park YJ, Tortorici MA, Wall A, McGuire AT, Veesler D (2020) Structure, function, and antigenicity of the SARS-CoV-2 spike glycoprotein. Cell 180:281-292. https://doi.org/10.1016/j. cell.2020.02.05

36. Wee LE et al (2020) Community-acquired viral respiratory infections amongst hospitalized inpatients during a COVID-19 outbreak in Singapore: co-infection and clinical outcomes. J Clin Virol 128: 104436

37. WHO Director-General's opening remarks at the media briefing on COVID-19-11 March 2020. https://www.who.int/dg/speeches/ detail/who-director-general-s-opening-remarks-at-the-mediabriefing-on-covid-19\%2D\%2D-11-march-2020

38. Wysocki J, Ye M, Rodriguez E, Gonzalez-Pacheco FR, Barrios C, Evora K, Schuster M, Loibner H, Brosnihan KB, Ferrario CM et al (2010) Targeting the degradation of angiotensin ii with recombinant angiotensin-converting enzyme 2: prevention of angiotensin iidependent hypertension. Hypertension 55:90-98
39. Xu H, Zhong L, Deng J, Peng J, Dan H, Zeng X, Li T, Chen Q (2020) High expression of ace2 receptor of 2019-ncov on the epithelial cells of oral mucosa. Int J Oral Sci 12:8

40. Zhao LQ, Qian Y, Zhu RN, Deng J, Wang F, Chen HZ, Cao L, Wang TY, Zhang T (2006) [Serological analysis of SARS coronavirus in children diagnosed clinically as severe acute respiratory syndrome cases during SARS epidemic in Beijing]. [Article in Chinese]. Zhonghua Er Ke Za Zhi 44(4):262-266

41. Zimmermann P, Curtis N (2020) Coronavirus infections in children including COVID-19. An overview of the epidemiology, clinical features, diagnosis, treatment and prevention options in children. Pediatr Infect Dis J 39(5):355-368

Publisher's note Springer Nature remains neutral with regard to jurisdictional claims in published maps and institutional affiliations. 